\title{
BMJ Open Prevalence, risk factors and associated ocular diseases of cerebral stroke: the population-based Beijing Eye Study
}

\author{
Ya Xing Wang, ${ }^{1}$ Wen Bin Wei, ${ }^{2}$ Liang Xu, ${ }^{1}$ Jost B Jonas (D) ${ }^{1,3}$
}

To cite: Wang YX, Wei WB, $\mathrm{Xu} \mathrm{L}$, et al. Prevalence, risk factors and associated ocular diseases of cerebral stroke: the population-based Beijing Eye Study. BMJ Open 2020;10:e024646. doi:10.1136/ bmjopen-2018-024646

- Prepublication history for this paper is available online. To view these files, please visit the journal online (http://dx.doi org/10.1136/bmjopen-2018024646).

Received 11 June 2018 Revised 28 February 2019 Accepted 08 March 2019
Check for updates

(C) Author(s) (or their employer(s)) 2020. Re-use permitted under CC BY-NC. No commercial re-use. See rights and permissions. Published by BMJ.

For numbered affiliations see end of article.

Correspondence to

Dr Wen Bin Wei;

tr_weiwenbin@163.com

\section{ABSTRACT}

Objective To assess the prevalence of cerebral stroke in the general population of Beijing and its association with systemic risk factors and ocular diseases.

Setting The population-based Beijing Eye Study was conducted in a rural and urban region of Beijing.

Participants With eligibility criteria of age $50+$ years and living in the study regions, 3468 subjects $(78.8 \%)$ out of 4403 eligible individuals participated.

Primary and secondary outcome measures The study participants underwent a detailed systemic and ophthalmological examination and an interview in which the occurrence of a previous stroke was assessed. Results A previous stroke was reported by 235 individuals (7.33\%; $95 \% \mathrm{Cl} 6.43 \%$ to $8.24 \%$ ). The prevalence of previous stroke increased from $2.0 \%$ (95\% $\mathrm{Cl} 0.9 \%$ to $3.1 \%$ ) in the age group of 50 to $<55$ years to $21.9 \%(95 \% \mathrm{Cl} 16.4 \%$ to $27.4 \%)$ in the age group of $80+$ years. In multivariable regression analysis, a higher prevalence of previous stroke was correlated (Nagelkerke $R^{2}=0.20$ ) with the systemic parameters of older age ( $p<0.001$; OR 1.06; $95 \% \mathrm{Cl} 1.04$ to 1.08), male gender $(p<0.001 ;$ OR $0.54 ; 95 \% \mathrm{Cl} 0.40$ to 0.74$)$, lower quality of life score $(p<0.001 ; 0 R 1.39 ; 95 \% \mathrm{Cl} 1.25$ to 1.55$)$, higher prevalence of arterial hypertension $(p<0.001 ; 0 R$ 2.86; $95 \% \mathrm{Cl} 2.05$ to 3.98 ), and cardiovascular disease ( $p<0.001$; OR 1.8554; $95 \% \mathrm{Cl} 1.34$ to 2.56 ), and with the ocular parameter of higher prevalence of diabetic retinopathy $(p<0.001 ; 0 \mathrm{R} 4.41 ; 95 \% \mathrm{Cl} 2.38$ to 8.18$)$ or alternatively, with higher stage of diabetic retinopathy $(p<0.001$; OR 1.64; 95\% Cl 1.26 to 2.14).

Conclusions In this North Chinese population aged $50+$ years, the prevalence of a previous stroke was $7.33 \%$ (95\% Cl 6.43\% to 8.24\%). After adjusting for systemic risk factors of older age, male gender and higher prevalence of arterial hypertension and cardiovascular disease, a higher prevalence of a previous stroke was significantly correlated with a higher prevalence and stage of diabetic retinopathy. The prevalence of a previous stroke increased for each step of an increase in the stage of diabetic retinopathy with an $\mathrm{OR}$ of $1.64(95 \% \mathrm{Cl} 1.26$ to 2.14$)$, and it increased by the presence of diabetic retinopathy with an OR of 4.41 (95\% Cl 2.38 to 8.18$)$.

\section{INTRODUCTION}

Cerebral stroke as one of the main contributors of the global burden of disease has caused 116 million or $4.8 \%$ of all disability-adjusted
Strengths and limitations of this study

- Population-based study design.

- Large number of parameters including ophthalmological variables assessed.

- Data on the prevalence of a previous stroke depended on self-reported information; patients who had died as a sequel of a previous stroke were not included into the study; the results of our study are therefore valid primarily only for stroke survivors.

- Intracerebral haemorrhage was not differentiated from ischaemic stroke.

c Cross-sectional analysis.

life years (DALY) and 14.5 million or $1.8 \%$ of all years lived with disability worldwide in the year 2013. ${ }^{1-4}$ In particular, China has witnessed a marked increase in the importance of stroke in the spectrum of diseases causing DALYs and years of life lost (YLL). While in 1990, lower respiratory infections or preterm birth complications were the leading causes of YLLs in almost half of the provinces of China (16 out of 33), cerebrovascular disease was the leading cause in 27 of the 33 provinces in $2013 .{ }^{56}$ Since the eye and the brain share the same arterial blood supply through the inner carotid artery and since the retina and the optic nerve as former outgrowth of the anterior end of the embryological neural groove are of neuroectodermal origin, a major cerebral disease such as stroke may be associated with ocular diseases, in particular disorders of the optic nerve and retina. Since comprehensive population-based studies on associations between stroke and ocular parameters have been scarce so far and have not been conducted for the population of China, we investigated the prevalence of cerebral stroke and its potential associations with ocular diseases, after adjusting for systemic factors, in a population-based study performed in China. 


\section{METHODS}

The Beijing Eye Study 2011 is a population-based study which was conducted in a rural region and an urban area of Greater Beijing. The eligibility criteria for inclusion into the study were age $50+$ years and living in the study regions. Out of 4403 eligible individuals, 3468 subjects (1963 $(56.6 \%)$ women) participated (response rate: $78.8 \%$ ). The mean age was $64.6 \pm 9.8$ years (median 64 years; range: $50-93$ years). There were $1633(47.1 \%)$ individuals (943 (57.7\%) women) coming from the rural region, with the remaining 1835 (52.9\%) study participants (1020 (55.6\%) women) living in the urban region. The study design has been described in detail previously. ${ }^{78}$

All study participants underwent a structured interview by trained research technicians. The interview included more than 200 standardised questions on demographic parameters, socioeconomic background, diet and alcohol consumption, smoking habits, known major systemic diseases and current systemic medical therapies. Using the Mini-Mental State Examination scale, we assessed the cognitive function. Fasting blood samples were collected for measurement of blood lipids, glucose, glycosylated haemoglobin (HbAlc) and serum creatinine. The blood pressure was measured with the participant sitting for at least $5 \mathrm{~min}$. We also measured body height and weight and the circumference of the waist and hip.

Arterial hypertension was defined by a systolic blood pressure $\geq 160 \mathrm{~mm} \mathrm{Hg}$ and/or a diastolic blood pressure $\geq 95 \mathrm{~mm} \mathrm{Hg}$, and/or self-reported current treatment for arterial hypertension with antihypertensive medication. Diabetes mellitus was characterised by a blood glucose concentration $\geq 7.0 \mathrm{mmol} / \mathrm{L}$, an $\mathrm{HbAlc}$ value $\geq 6 \%$, by a self-reported history of physician diagnosis of diabetes mellitus, or by a history of drug treatment for diabetes (insulin or oral hypoglycaemic agents). Depressive symptoms were evaluated using a Chinese Depression Scale adapted from the Zung Self-Rated Depression Scale. ${ }^{9}$ The prevalence of previous stroke was examined in the interview by standardised questions on whether a previous cerebral stroke had occurred with typical symptoms such as sudden-onset face weakness, arm drift, abnormal speech hemiplegia, or numbness for at least 24 hours, when such a stroke had occurred and whether it had been treated.

The ophthalmological examination consisted of automatic refractometry (Auto Refractometer AR-610; Nidek, Tokyo, Japan), measurement of presenting visual acuity, uncorrected visual acuity and best-corrected visual acuity, tonometry, slit lamp-based biomicroscopy of the anterior and posterior segments of the eyes, and photography of the cornea and lens (Neitz CT-R camera; Neitz Instruments, Tokyo, Japan) and of the macula and optic disc (fundus camera; Type CR6-45MM; Canon, Tokyo, Japan) in medical mydriasis. Using the photographs, we measured the dimensions of the optic disc, optic cup and parapapillary alpha, beta and gamma zones. The optic nerve head and macula were additionally examined by spectral domain optical coherence tomography using the enhanced depth imaging modality (Spectralis; Heidelberg
Engineering, Heidelberg, Germany). We determined the thickness of the peripapillary retinal nerve fibre layer of the retina in the foveal region and of the subfoveal choroid. Applying optical low-coherence reflectometry (Lenstar 900 Optical Biometer; Haag-Streit, Koeniz, Switzerland), we measured ocular biometric parameters such as the anterior corneal curvature, central corneal thickness, anterior chamber depth, lens thickness and axial length. The degree of cataract was determined using the lens photographs. The degree of nuclear opacities was assessed in six grades using the grading system of the Age-Related Eye Disease Study. ${ }^{10}$ In addition, retroilluminated photographs of the lens were obtained (Neitz CT-R camera; Neitz Instruments), and the percentage of the areas with cortical and posterior subcapsular lens opacities was measured using a grid. The standard to diagnose a nuclear cataract was a nuclear cataract grade of 4 or more, the standard to diagnose a posterior subcapsular cataract was an amount of posterior subcapsular opacities of 0.01 or more and the standard to diagnose a cortical cataract was an amount of cortical opacities of 0.05 or more. The degree of fundus tessellation defined as the visibility of the large choroidal vessels was assessed on the fundus photographs of the macula and of the optic disc as described in detail previously. ${ }^{8}$ It was graded using a scale which ranged from ' 0 ' for 'no tessellation' to ' 3 ' for 'marked tessellation'. Diabetic retinopathy was assessed on the fundus photographs using the Early Treatment of Diabetic Retinopathy Study criteria. The minimum criterion for diagnosis of diabetic retinopathy was the presence of at least one microaneurysm. The diagnosis for each individual was based on the grading of the individual's eye with the highest stage of diabetic retinopathy. We differentiated between the mild non-proliferative stage, the moderate non-proliferative stage, the advanced non-proliferative stage and the proliferative stage of diabetic retinopathy. Glaucomatous optic neuropathy was defined using the criteria of the International Society of Geographic and Epidemiological Ophthalmology. ${ }^{11}$ Pseudoexfoliation was assessed by an experienced ophthalmologist during the slit lamp assisted biomicroscopy of the anterior segment after pupillary dilation. The diagnosis of pseudoexfoliation was definite, if the lens surface showed a central whitish coating with a diameter of little less than the normal pupillary diameter, or if the periphery of the lens surface showed a whitish coating which was anteriorly bordered by a darker ring-like region on the lens surface. The assessment of pseudoexfoliation was performed only in phakic eyes. For the diagnosis of age-related macular degeneration, the International ARM (age-related maculopathy) Epidemiological Study Group grading system was used. The subjective symptoms of dry eye were evaluated using a questionnaire composed of three questions: 'Do your eyes ever feel dry?'; 'Do you ever feel a gritty or sandy sensation in your eyes?'; and 'Do your eyes ever have a burning sensation?' Possible answers to the questions were none $(0)$, less than once a month (1), once or twice a week (2), at least once every day (3), all the 
time (4). The presence of dry eye symptoms was defined as having one or more symptoms at least once every day (3 and 4). A quantitative grading score of subjective dry eye symptoms was obtained by summarising the answers to the different questions $(0-12) .{ }^{12}$

The statistical analysis was performed using a commercially available statistical software package (SPSS for Windows, V.25.0, IBM-SPSS). Data were shown as mean (SD), frequency $(\%, 95 \% \mathrm{CI})$ or median (IQR) where appropriate. The differences in parameters such as age and sex between participants with stroke and participants without stroke were assessed by the Student's t-test for unpaired samples or by the $\chi^{2}$ test. We tested associations between baseline characteristics and stroke with logistic regression adjusting for age and sex. Significant covariates from the step above $(\mathrm{p}<0.10)$ were included in multivariable models. We reduced the full model by successively removing non-significant covariates until all remaining predictors remained statistically significant $(p<0.05)$. We calculated the OR. All $p$ values were two sided and considered statistically significant, if the values were less than 0.05 .

\section{Patient and public involvement}

Patients were not involved in this study.

\section{RESULTS}

Out of 3468 study participants, 3205 (92.4\%) individuals participated in the interview with available information on previous stroke and underwent the systemic and ophthalmological examination. The participating group as compared with the group of individuals without available information on previous stroke or without systemic and ocular examination was significantly younger (64.4 \pm 9.7 years (median: 63 years; range: $50-93$ years) vs $67.1 \pm 11.1$ years; $p<0.001)$ and came significantly more often from the urban region than from the rural area (rural/urban region of habitation: 1439/1766 vs 194/69; $\mathrm{p}<0.001$ ), while the differences in gender (men/women: $1386 / 1819$ vs $119 / 144 ; \mathrm{p}=0.56)$, axial length $(23.3 \pm 1.1 \mathrm{~mm}$ vs $23.2 \pm 1.9 \mathrm{~mm} ; \mathrm{p}=0.31)$ and refractive error $(-0.22 \pm 2.12$ dioptres vs $-0.31 \pm 2.17$ dioptres; $\mathrm{p}=0.59$ ) were not statistically significant.

A previous stroke was reported by 235 individuals (235/3205 or $7.33 \%$ (95\% CI $6.43 \%$ to $8.24 \%$ )). Among the 235 patients, 192 individuals were on oral medication for the prophylaxis of a recurrence of the stroke. The stroke had taken place $7.5 \pm 5.7$ years ago (median: 7 years; range: 1 month to 26 years).

In the stroke group as compared with the non-stroke group (control group), age was significantly older $(71.1 \pm 9.2$ years vs $63.9 \pm 9.5$ years; $\mathrm{p}<0.001)$ and had a higher proportion of men than women (men/women: $128 / 107$ vs $1258 / 1712 ; \mathrm{p}<0.001$ ) (figure 1 ). The prevalence of a previous stroke increased from $2.0 \%$ (95\% CI $0.9 \%$ to $3.1 \%$ ) in the age group of 50 to $<55$ years, to $6.9 \%$ $(95 \%$ CI $4.5 \%$ to $9.2 \%)$ in the age group of 65 to $<70$

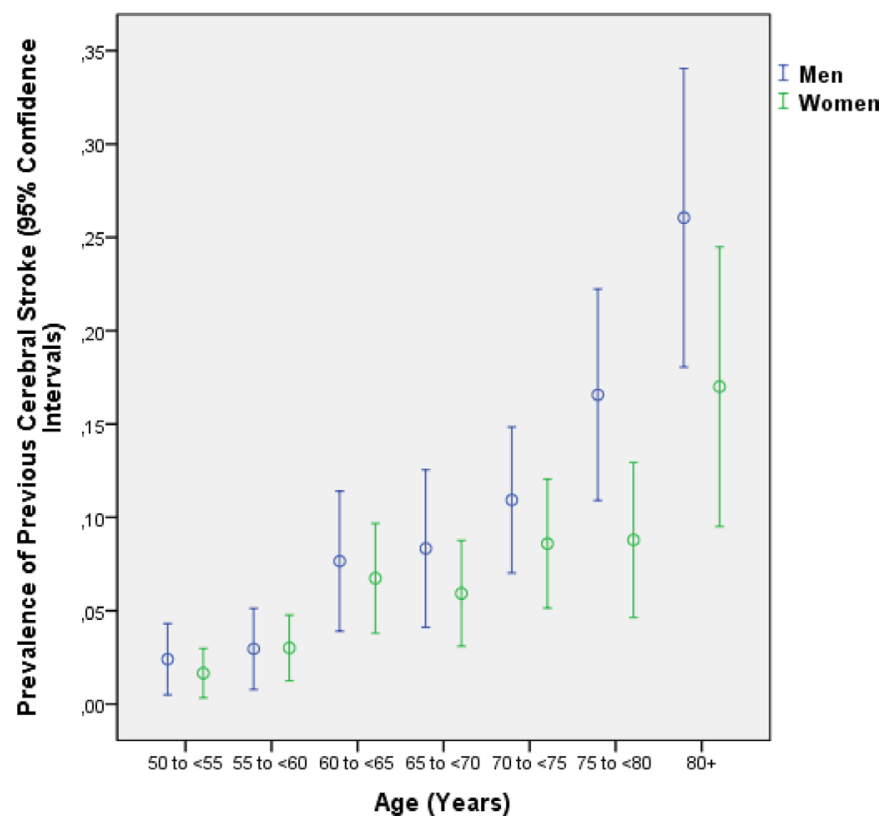

Figure 1 Graph showing the distribution of the prevalence of a previous cerebral stroke stratified by age and gender in the Beijing Eye Study.

years and to $21.9 \%$ (95\% CI $16.4 \%$ to $27.4 \%$ ) in the age group of $80+$ years (table 1 ).

Since many systemic and ocular parameters were age related, we performed in a next step of the statistical examination a binary regression analysis with the prevalence of stroke as the dependent parameter and other systemic and ocular parameters as single independent variables, with adjusting for age and gender (table 2). In that analysis, a higher prevalence of stroke was associated with the systemic parameters of higher body mass index $(p=0.03)$, lower frequency of alcohol consumption $(p=0.001)$, lower number of days with vigorous physical activities $(\mathrm{p}=0.05)$ or moderately intensive physical activities $(p=0.01)$ and higher number of hours spent with sitting per day $(\mathrm{p}=0.04)$, lower life quality score $(\mathrm{p}<0.001)$, higher depression score $(\mathrm{p}<0.001)$, higher blood concentration of glucose $(\mathrm{p}=0.01)$ and HbAlc $(\mathrm{p}=0.008)$, and higher prevalence of diabetes mellitus $(\mathrm{p}<0.001)$ and arterial hypertension $(\mathrm{p}<0.001)$; and with the ocular parameters of thicker central corneal thickness $(\mathrm{p}=0.09)$, lower foveal thickness $(\mathrm{p}=0.04)$, higher incidence of localised retinal nerve fibre layer defects $(\mathrm{p}=0.06)$, dry eye feeling $(\mathrm{p}=0.08)$, and higher prevalence of keratoconus $(\geq 49$ dioptres $)(\mathrm{p}=0.02)$, nuclear cataract $(\mathrm{p}=0.06)$ and presence and stage diabetic retinopathy $(\mathrm{p}<0.001)$ (table 2$)$ (figure 2).

The multivariable analysis included the prevalence of previous stroke as dependent variable and as independent variables all those systemic parameters for which the $\mathrm{p}$ value in the previous analysis was $<0.10$ (table 2 ). We then dropped in step-by-step manner all independent parameters (such as the prevalence of diabetes mellitus) which either showed a collinearity with one of the other independent variables or which were no longer 
Table 1 Prevalence (mean and 95\% Cl) of previous stroke in the Beijing Eye Study

\begin{tabular}{|c|c|c|c|c|c|c|}
\hline \multirow{2}{*}{$\begin{array}{l}\text { Age group } \\
\text { (years) }\end{array}$} & \multicolumn{2}{|l|}{ Men } & \multicolumn{2}{|c|}{ Women } & \multicolumn{2}{|c|}{ Total } \\
\hline & $\mathbf{n}$ & Prevalence & $\mathbf{n}$ & Prevalence & $\mathbf{n}$ & Prevalence \\
\hline 50 to $<55$ & 250 & $2.5 \%(0.5 \%$ to $4.3 \%)$ & 363 & $1.7 \%(0.3 \%$ to $3.0 \%)$ & 613 & $2.0 \%(0.9 \%$ to $3.1 \%)$ \\
\hline 60 to $<65$ & 196 & $7.7 \%(3.9 \%$ to $11.4 \%)$ & 282 & $6.7 \%(3.8 \%$ to $9.7 \%)$ & 478 & $7.1 \%(4.8 \%$ to $9.4 \%)$ \\
\hline 65 to $<70$ & 168 & $8.3 \%(4.1 \%$ to $12.6 \%)$ & 270 & $5.9 \%(3.1 \%$ to $8.8 \%)$ & 438 & $6.9 \%(4.5 \%$ to $9.2 \%)$ \\
\hline 75 to $<80$ & 169 & $16.6 \%(10.9 \%$ to $22.2 \%)$ & 182 & $8.8 \%$ (4.6 to 12.9$)$ & 351 & $12.5 \%(9.1 \%$ to $16.0 \%)$ \\
\hline $80+$ & 119 & $26.1 \%(18.1 \%$ to $34.1 \%)$ & 100 & $17.0 \%(9.5 \%$ to $24.5 \%)$ & 219 & $21.9 \%(16.4 \%$ to $27.4 \%)$ \\
\hline
\end{tabular}

statistically significantly correlated with the prevalence of a previous stroke. In the final model, a higher prevalence of previous stroke was correlated (Nagelkerke $R^{2}=0.20$ ) with older age $(p<0.001)$, male gender $(p<0.001)$, lower quality of life score $(\mathrm{p}<0.001)$, higher prevalence of arterial hypertension $(p<0.001)$ and cardiovascular disease $(\mathrm{p}<0.001)$, and higher prevalence of diabetic retinopathy $(\mathrm{p}<0.001)$ (table 3$)$. If the parameter of prevalence of diabetic retinopathy was replaced by the diabetic retinopathy stage, the latter was associated with previous stroke $(\mathrm{p}<0.001 ;$ OR $1.64 ; 95 \%$ CI 1.26 to 2.14$)$.

\section{DISCUSSION}

In our population-based study on a population aged $50+$ years in Greater Beijing, the prevalence of a previous stroke was $7.33 \%$ (95\% CI $6.43 \%$ to $8.24 \%$ ). After adjusting for the systemic risk factors of older age, male gender and a higher prevalence of arterial hypertension and cardiovascular disease, a higher prevalence of a previous stroke was significantly correlated with the presence and a higher stage of diabetic retinopathy (figure 2). The prevalence of a previous stroke increased for each increase in the stage of diabetic retinopathy (with altogether four stages) by an OR of 1.64 (95\% CI 1.26 to 2.14), and for the presence of diabetic retinopathy by an OR of $4.41(95 \%$ CI 2.38 to 8.18 ).

The findings obtained in our study agree with the results of previous investigations. In a review of studies conducted since 1990 in Chinese populations, Tsai and colleagues reported on an age-standardised annual first-ever stroke incidence of 205-584 per 100000 in Chinese for the age group of $45-74$ years. ${ }^{13} \mathrm{Li}$ and colleagues, performing a population-based stroke surveillance on more than 14000 residents in Tianjin, China from 1992 to 2012, reported on an increase in the age-standardised incidence for both intracerebral haemorrhage (37.8 per 100000 person-years in 1992-1998; 46.5 in 1999-2005; and 76.5 in 2006-2012) and for ischaemic stroke (83.9 in 19921998; 135.3 in 1999-2005; and 238.0 in 2006-2012). ${ }^{14}$ The age-standardised incidence of first-ever stroke increased annually by $4.9 \%$ for intracerebral haemorrhage and by $7.3 \%$ for ischaemic stroke. In a similar study, Ning and associates found that the age-standardised incidence of first-ever stroke per 100000 person-years increased significantly from 122 in the years 1992-1999 to 216 in 20002007, and to 471.8 in $2008-2015 .^{15}$ The greatest increases were observed in adults aged 55-64 years. In the China National Stroke Screening Survey as reported by Guan and coworkers, the adjusted stroke prevalence in 2014 was $2.06 \%$ in adults aged 40 years and older. ${ }^{16}$ The incidence of first-ever stroke in adults aged 40-74 years increased from 189/100 000 individuals in 2002 to $379 / 100000$ in 2013 - an overall annual increase of $8.3 \%$.

The systemic factors associated with the prevalence of a previous stroke in our study population were similar to those reported in previous investigations: older age, male gender and a higher prevalence of arterial hypertension and cardiovascular disease. In the China National Stroke Screening Survey, the largest contributor as risk factor was arterial hypertension (population-attributable risk $53.2 \%$ ), followed by family history, dyslipidaemia, atrial fibrillation, diabetes, physical inactivity, smoking and overweight/obesity. ${ }^{16}$

The interesting finding in our study is that, after adjusting for other systemic risk factors, the presence of diabetic retinopathy increased the likelihood of a previous stroke by an OR of 4.41 , and in a parallel manner, that an increase by one step in the stage of diabetic retinopathy increased the probability of a previous stroke by an OR of 1.64. In previous studies by Cheung $e t$ al and by Petitti and Bhatt, a similar association was described. ${ }^{17} 18$ In a population-based, prospective cohort study of 1617 middle-aged persons with diabetes, Cheung et al found that after a mean follow-up of 7.8 years diabetic retinopathy was associated with an increased risk of ischaemic stroke (hazard rate ratio, 2.34; $95 \%$ CI 1.13 to 4.86 ), after adjusting for systemic parameters such as age, gender, race, arterial blood pressure, duration and therapy of diabetes, blood lipid concentrations and levels, and cigarette smoking status. ${ }^{17}$ In an earlier study, Petitti and Bhatt found in a nested case-control study that the estimated relative risk of stroke in diabetic subjects with retinopathy was 4.0 (95\% CI 1.0 to 14.5) after adjustment for systemic risk factors. ${ }^{18}$ The reason for this association may be that diabetic retinopathy as a microangiopathy indicates a widespread vascular disorder. 
Table 2 Associations between the prevalence of cerebral stroke and systemic and ocular parameters after adjusting for age and gender in the Beijing Eye Study 2011

\begin{tabular}{|c|c|c|c|}
\hline Parameter & $P$ value & OR & $95 \% \mathrm{Cl}$ \\
\hline \multicolumn{4}{|l|}{ Systemic parameters } \\
\hline Rural/urban region of habitation & 0.11 & 1.29 & 0.95 to 1.75 \\
\hline Body mass index $\left(\mathrm{kg} / \mathrm{m}^{2}\right)$ & 0.03 & 1.04 & 1.001 to 1.08 \\
\hline Level of education (1-5) & 0.64 & 1.04 & 0.92 to 1.18 \\
\hline Self-reported income & 0.73 & 0.99 & 0.93 to 1.05 \\
\hline Cognitive score & 0.77 & 1.00 & 0.96 to 1.03 \\
\hline Alcohol consumption frequency & 0.001 & 0.85 & 0.77 to 0.94 \\
\hline Smoking: never/former/current & 0.19 & 0.87 & 0.71 to 1.07 \\
\hline Smoking: never/ever & 0.98 & 1.00 & 0.72 to 1.38 \\
\hline Smoking package years & 0.38 & 1.00 & 1.00 to 1.01 \\
\hline \multicolumn{4}{|l|}{ Physical activity } \\
\hline ‘How many days do you walk?' & 0.51 & 0.98 & 0.92 to 1.04 \\
\hline $\begin{array}{l}\text { 'How many days do you do vigorously } \\
\text { intensive sport or activities?' }\end{array}$ & 0.05 & 0.81 & 0.66 to 1.00 \\
\hline $\begin{array}{l}\text { 'How many days do you do moderately } \\
\text { intensive sport or activities?' }\end{array}$ & 0.01 & 0.94 & 0.89 to 0.99 \\
\hline 'How many hours do you sit per day?' & 0.04 & 1.06 & 1.004 to 1.12 \\
\hline \multicolumn{4}{|l|}{ Quality of life } \\
\hline Summed score & $<0.001$ & 1.44 & 1.31 to 1.59 \\
\hline $\begin{array}{l}\text { Mobility: I have no/some problems in } \\
\text { walking about/I am confined to bed }\end{array}$ & $<0.001$ & 2.79 & 2.01 to 3.86 \\
\hline $\begin{array}{l}\text { Self-care: I have no/some problems in } \\
\text { washing or dressing myself/I am unable } \\
\text { to wash or dress myself }\end{array}$ & $<0.001$ & 3.33 & 2.33 to 4.75 \\
\hline $\begin{array}{l}\text { Usual activities (eg, work, study, } \\
\text { housework, family or leisure activities): I } \\
\text { am able to wash or dress myself/I have } \\
\text { some problems with performing my } \\
\text { usual activities/l am unable to perform } \\
\text { my usual activities }\end{array}$ & $<0.001$ & 3.27 & 2.36 to 4.53 \\
\hline Pain/discomfort & 0.001 & 1.62 & 1.22 to 2.14 \\
\hline $\begin{array}{l}\text { Anxiety/depression: I am not/ } \\
\text { moderately/extremely anxious or } \\
\text { depressed }\end{array}$ & $<0.001$ & 2.07 & 1.45 to 2.95 \\
\hline Depression score & $<0.001$ & 1.06 & 1.04 to 1.08 \\
\hline \multicolumn{4}{|l|}{ Blood concentration of } \\
\hline Glucose (mmol/L) & 0.01 & 1.11 & 1.02 to 1.21 \\
\hline Glycosylated haemoglobin (HbA1c) & 0.008 & 1.18 & 1.04 to 1.33 \\
\hline High-density lipoproteins ( $\mathrm{mmol} / \mathrm{L}$ ) & 0.11 & 0.70 & 0.45 to 1.09 \\
\hline Low-density lipoproteins (mmol/L) & 0.28 & 0.90 & 0.74 to 1.09 \\
\hline Triglycerides (mmol/L) & 0.95 & 1.01 & 0.86 to 1.17 \\
\hline Cholesterol (mmol/L) & 0.18 & 0.88 & 0.74 to 1.06 \\
\hline C-reactive protein & 0.47 & 1.01 & 0.98 to 1.04 \\
\hline Diabetes mellitus, prevalence & $<0.001$ & 1.86 & 1.32 to 2.61 \\
\hline Diabetes mellitus, duration (years) & 0.08 & 1.02 & 1.00 to 1.04 \\
\hline Systolic blood pressure $(\mathrm{mm} \mathrm{Hg})$ & 0.14 & 1.01 & $1.00,1.02$ \\
\hline Diastolic blood pressure $(\mathrm{mm} \mathrm{Hg})$ & 0.82 & 1.00 & 0.99 to 1.01 \\
\hline Mean blood pressure (mm Hg) & 0.40 & 1.00 & 0.99 to 1.01 \\
\hline Arterial hypertension & $<0.001$ & 2.42 & 1.76 to 3.34 \\
\hline $\begin{array}{l}\text { Estimated cerebrospinal fluid pressure } \\
(\mathrm{mm} \mathrm{Hg})\end{array}$ & 0.17 & 1.03 & 0.99 to 1.09 \\
\hline Creatinine (mmol/L) & 0.67 & 1.00 & 0.99 to 1.02 \\
\hline $\begin{array}{l}\text { Estimated glomerular filtration rate (GFR) } \\
\left(\mathrm{mL} / \mathrm{min} / 1.73 \mathrm{~m}^{2}\right) \text { (MDRD formula) }\end{array}$ & 0.79 & 1.00 & 0.99 to 1.01 \\
\hline
\end{tabular}

Continued

\begin{tabular}{|c|c|c|c|}
\hline Parameter & $P$ value & OR & $95 \% \mathrm{Cl}$ \\
\hline $\begin{array}{l}\text { Estimated glomerular filtration rate (mL/ } \\
\left.\mathrm{min} / 1.73 \mathrm{~m}^{2}\right)(\text { CKD-EPI formula) }\end{array}$ & 0.79 & 1.00 & 0.98 to 1.01 \\
\hline \multicolumn{4}{|l|}{ Ocular parameters } \\
\hline Refractive error (dioptres) & 0.47 & 0.98 & 0.92 to 1.04 \\
\hline Axial length (mm) & 0.70 & 0.98 & 0.86 to 1.11 \\
\hline Anterior corneal curvature radius $(\mathrm{mm})$ & 0.16 & 0.66 & 0.37 to 1.18 \\
\hline Central corneal thickness $(\mu \mathrm{m})$ & 0.09 & 1.004 & 0.999 to 1.008 \\
\hline Anterior chamber depth $(\mathrm{mm})$ & 0.92 & 1.01 & 0.79 to 1.29 \\
\hline Lens thickness $(\mathrm{mm})$ & 0.14 & 1.41 & 0.89 to 2.22 \\
\hline Intraocular pressure $(\mathrm{mm} \mathrm{Hg})$ & 0.66 & 1.01 & 0.96 to 1.06 \\
\hline Retinal nerve fibre layer thickness $(\mu \mathrm{m})$ & 0.62 & 1.00 & 0.99 to 1.01 \\
\hline $\begin{array}{l}\text { Localised defects of the retinal nerve } \\
\text { fibre layer, prevalence }\end{array}$ & 0.42 & 1.18 & 0.79 to 1.77 \\
\hline $\begin{array}{l}\text { Localised defects of the retinal nerve } \\
\text { fibre layer, 10-year incidence }\end{array}$ & 0.06 & 1.83 & 0.98 to 3.42 \\
\hline Subfoveal choroidal thickness $(\mu \mathrm{m})$ & 0.83 & 1.00 & 1.00 to 1.00 \\
\hline Fundus tessellation & 0.66 & 1.02 & 0.92 to 1.13 \\
\hline Macular retinal thickness $(\mu \mathrm{m})$ & 0.04 & 0.994 & 0.989 to 1.000 \\
\hline Optic disc size $\left(\mathrm{mm}^{2}\right)$ & 0.69 & 1.09 & 0.71 to 1.70 \\
\hline Neuroretinal rim area $\left(\mathrm{mm}^{2}\right)$ & 0.52 & 1.15 & 0.75 to 1.77 \\
\hline Dry eye, yes or no & 0.80 & 1.04 & 0.79 to 1.36 \\
\hline Dry eye, number of days & 0.08 & 1.04 & 0.995 to 1.10 \\
\hline $\begin{array}{l}\text { Keratoconus (anterior corneal curvature } \\
\text { refractive power } \geq 48 \text { dioptres) }\end{array}$ & 0.27 & 2.04 & 0.58 to 7.18 \\
\hline $\begin{array}{l}\text { Keratoconus (anterior corneal curvature } \\
\text { refractive power } \geq 49 \text { dioptres) }\end{array}$ & 0.02 & 8.00 & 1.31 to 48.9 \\
\hline Pseudoexfoliation syndrome & 0.49 & 0.82 & 0.47 to 1.43 \\
\hline Nuclear cataract & 0.06 & 0.72 & 0.51 to 1.02 \\
\hline Cortical cataract & 0.87 & 0.97 & 0.66 to 1.43 \\
\hline Subcapsular posterior cataract & 0.34 & 1.29 & 0.77 to 2.16 \\
\hline Glaucoma, prevalence, total & 0.61 & 0.87 & 0.52 to 1.47 \\
\hline Open-angle glaucoma & 0.26 & 0.63 & 0.28 to 1.40 \\
\hline Primary angle closure glaucoma & 0.36 & 0.57 & 0.17 to 1.89 \\
\hline $\begin{array}{l}\text { Age-related macular degeneration, } \\
\text { prevalence, total }\end{array}$ & 0.60 & 0.92 & 0.68 to 1.25 \\
\hline $\begin{array}{l}\text { Age-related macular degeneration, early } \\
\text { stage }\end{array}$ & 0.29 & 0.75 & 0.44 to 1.28 \\
\hline $\begin{array}{l}\text { Age-related macular degeneration, } \\
\text { intermediate stage }\end{array}$ & 0.75 & 0.95 & 0.67 to 1.34 \\
\hline $\begin{array}{l}\text { Age-related macular degeneration, late } \\
\text { stage }\end{array}$ & 0.11 & 2.26 & 0.84 to 6.06 \\
\hline Diabetic retinopathy, prevalence & $<0.001$ & 1.63 & 1.27 to 2.08 \\
\hline Diabetic retinopathy, score & $<0.001$ & 4.75 & 2.67 to 8.46 \\
\hline Retinal vein occlusion, total & 0.18 & 1.55 & 0.82 to 2.93 \\
\hline Branch retinal vein occlusion & 0.65 & 1.25 & 0.48 to 3.29 \\
\hline Myopic retinopathy & 0.77 & 1.20 & 0.36 to 4.03 \\
\hline
\end{tabular}

MDRD: Modification of Diet in Renal Disease; CKD-EPI: Chronic Kidney Disease Epidemiology Collaboration

When discussing the results of our study, its limitations have to be taken into account. First, the data on the prevalence of a previous self-reported stroke depended on the information provided by the study participants in the face-to-face interviews. Since stroke is a dramatic event, it is unlikely to be under-reported. Transient 


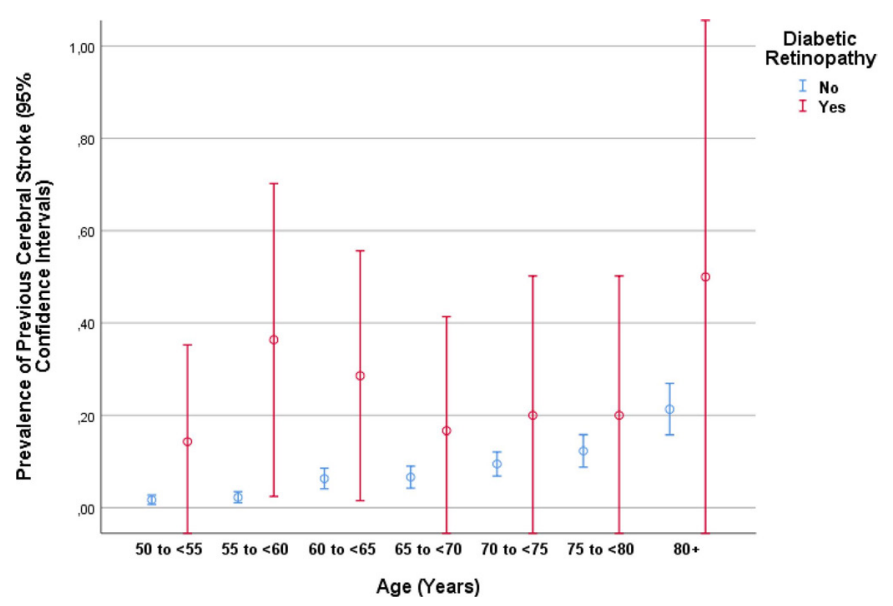

Figure 2 Graph showing the distribution of the prevalence of a previous cerebral stroke stratified by age and presence of diabetic retinopathy in the Beijing Eye Study.

ischaemic attacks might occur unnoticed by the individuals so that transient ischaemic attacks might be underreported in an interview of previous cerebral strokes. Our study was based however primarily on previous cerebral strokes which were defined as an occurrence of typical neurological symptoms for at least 24 hours. It may make it unlikely that unnoticed previous transient ischaemic attacks might have markedly influenced the results of our study. Second, patients who had died as a sequel of a previous stroke were not included into the study. The results of our study are therefore valid primarily only for stroke survivors. Third, due to regional differences in China, findings obtained in our study may not completely be transferable to South China or other world regions. ${ }^{19}$ Fourth, we did not differentiate between intracerebral haemorrhage and ischaemic stroke. ${ }^{20}$ Fifth, we did not assess the role of atrial fibrillation as risk factor for stroke in our study. Sixth, the study population with age 50+ years had experienced major societal changes and economic developments in China during their lifetime. This elderly generation may differ from the young generations in China

Table 3 Associations (multivariable analysis) between the prevalence of cerebral stroke and systemic and ocular parameters in the Beijing Eye Study 2011

\begin{tabular}{|c|c|c|c|}
\hline Parameter & $P$ value & OR & $95 \% \mathrm{Cl}$ \\
\hline Age (years) & $<0.001$ & 1.06 & 1.04 to 1.08 \\
\hline Gender (men/women) & $<0.001$ & 0.54 & 0.40 to 0.74 \\
\hline Inverse quality of life score & $<0.001$ & 1.39 & 1.25 to 1.55 \\
\hline $\begin{array}{l}\text { Prevalence of arterial } \\
\text { hypertension }\end{array}$ & $<0.001$ & 2.86 & 2.05 to 3.98 \\
\hline Cardiovascular disease & $<0.001$ & 1.85 & 1.34 to 2.56 \\
\hline $\begin{array}{l}\text { Prevalence of diabetic } \\
\text { retinopathy }\end{array}$ & $<0.001$ & 4.41 & 2.38 to 8.18 \\
\hline $\begin{array}{l}\text { (Alternatively: stage of } \\
\text { diabetic retinopathy) }\end{array}$ & $<0.001$ & 1.64 & 1.26 to 2.14 \\
\hline
\end{tabular}

and from populations in other countries. Seventh, our investigation was a cross-sectional observational study, so that a reverse causality may have existed in the sense that diabetic retinopathy might have been the sequel of stroke.

In conclusion, in this North Chinese population aged $50+$ years, the prevalence of a previous stroke was $7.33 \%$ (95\% CI $6.43 \%$ to $8.24 \%$ ). The presence and stage of diabetic retinopathy were ocular risk factors for a higher prevalence of a previous stroke, after adjusting for the systemic risk factors of older age, male gender and a higher prevalence of diabetes mellitus and cardiovascular disease. The prevalence of a previous stroke increased for each step of an increase in the stage of diabetic retinopathy with an OR of 1.64 (95\% CI 1.26 to $2.14)$, and it increased by the presence of diabetic retinopathy with an OR of 4.41 (95\% CI 2.38 to 8.18). Individuals with diabetic retinopathy appear to be a group at particularly high risk of cerebral stroke.

\section{Author affiliations}

${ }^{1}$ Beijing Institute of Ophthalmology, Beijing Tongren Eye Center, Beijing Tongren Hospital, Capital Medical University; Beijing Key Laboratory of Ophthalmology and Visual Sciences, Beijing, China

${ }^{2}$ Department of Ophthalmology, Beijing Tongren Eye Center, Beijing Key Laboratory of Intraocular Tumor Diagnosis and Treatment, Beijing Ophthalmology \& Visual Sciences Key Lab, Medical Artificial Intelligence Research and Verification Key Laboratory of the Ministry of Industry and Information Technology, Beijing Tongren Hospital, Capital Medical University, Beijing, China

${ }^{3}$ Department of Ophthalmology, Medical Faculty Mannheim of the Ruprecht-KarlsUniversity, Mannheim, Germany

Contributors Design and conception: YXW, WBW, LX, JBJ. Statistical analysis: YXW, JBJ. Writing of the manuscript: JBJ. Editing and final approval of the manuscript: YXW, WBB, LX, JBJ.

Funding This study was supported by the State Natural Sciences Fund (81041018) and the Natural Sciences Fund of Beijing government (7092021; 7112031).

Disclaimer The funders had no role in study design, data collection and analysis, decision to publish or preparation of the manuscript.

Competing interests None declared.

Patient consent for publication Not required.

Ethics approval The Medical Ethics Committee of the Beijing Tongren Hospital approved the study design, and all study participants gave an informed consent.

Provenance and peer review Not commissioned; externally peer reviewed.

Data availability statement Data are available upon reasonable request.

Open access This is an open access article distributed in accordance with the Creative Commons Attribution Non Commercial (CC BY-NC 4.0) license, which permits others to distribute, remix, adapt, build upon this work non-commercially, and license their derivative works on different terms, provided the original work is properly cited, appropriate credit is given, any changes made indicated, and the use is non-commercial. See: http://creativecommons.org/licenses/by-nc/4.0/.

ORCID iD

Jost B Jonas http://orcid.org/0000-0003-2972-5227

\section{REFERENCES}

1 GBD 2016 DALYs and HALE Collaborators. Global, regional, and national disability-adjusted life-years (DALYs) for 333 diseases and injuries and healthy life expectancy (HALE) for 195 countries and territories, 1990-2016: a systematic analysis for the global burden of disease study 2016. Lancet 2017;390:1260-344.

2 GBD 2016 Disease and Injury Incidence and Prevalence Collaborators. Global, regional, and national incidence, prevalence, 
and years lived with disability for 328 diseases and injuries for 195 countries, 1990-2016: a systematic analysis for the global burden of disease study 2016. Lancet 2017;390:1211-59.

3 Feigin VL, Mensah GA, Norrving B, et al. Stroke panel experts group. atlas of the global burden of stroke (1990-2013): the GBD 2013 study. Neuroepidemiology 2013;2015:230-6.

4 Feigin VL, Krishnamurthi RV, Parmar P, et al. Update on the global burden of ischemic and hemorrhagic stroke in 1990-2013: the GBD 2013 study. Neuroepidemiology 2015;45:161-76.

5 Zhou M, Wang H, Zhu J, et al. Cause-Specific mortality for 240 causes in China during 1990-2013: a systematic subnational analysis for the global burden of disease study 2013. Lancet 2016;387:251-72.

6 Feigin VL, Roth GA, Naghavi M, et al. Global burden of stroke and risk factors in 188 countries, during 1990-2013: a systematic analysis for the global burden of disease study 2013. Lancet Neurol 2016;15:913-24.

$7 \mathrm{Xu} \mathrm{J}, \mathrm{Xu} \mathrm{L}$, Du KF, et al. Subfoveal choroidal thickness in diabetes and diabetic retinopathy. Ophthalmology 2013;120:2023-8.

8 Yan YN, Wang YX, Xu L, et al. Fundus Tessellation: prevalence and associated factors: the Beijing eye study 2011. Ophthalmology 2015;122:1873-80.

9 ZUNG WW. A self-rating depression scale. Arch Gen Psychiatry 1965;12:63-70.

10 Age-Related Eye Disease Study Research Group. The age-related eye disease study (AREDS) system for classifying cataracts from Photographs: AREDS report No. 4. Am J Ophthalmol 2001;131:167-75.
11 Foster PJ, Buhrmann R, Quigley HA, et al. The definition and classification of glaucoma in prevalence surveys. Br J Ophthalmol 2002;86:238-42.

12 Jie Y, Xu L, Wu YY, et al. Prevalence of dry eye among adult Chinese in the Beijing eye study. Eye 2009;23:688-93.

13 Tsai C-F, Thomas B, Sudlow CLM. Epidemiology of stroke and its subtypes in Chinese vs white populations: a systematic review. Neurology 2013;81:264-72.

14 Li B, Lou Y, Gu H, et al. Trends in incidence of stroke and transition of stroke subtypes in rural Tianjin China: a population-based study from 1992 to 2012. PLoS One 2015;10:e0139461.

15 Ning X, Sun J, Jiang R, et al. Increased stroke burdens among the low-income young and middle aged in rural China. Stroke 2017;48:77-83.

16 Guan T, Ma J, Li M, et al. Rapid transitions in the epidemiology of stroke and its risk factors in China from 2002 to 2013. Neurology 2017;89:53-61

17 Cheung N, Rogers S, Couper DJ, et al. Is diabetic retinopathy an independent risk factor for ischemic stroke? Stroke 2007;38:398-401.

18 Petitti DB, Bhatt H. Retinopathy as a risk factor for nonembolic stroke in diabetic subjects. Stroke 1995;26:593-6.

19 Xu G, Ma M, Liu X, et al. Is there a stroke belt in China and why? Stroke 2013;44:1775-83.

20 Zhang L-F, Yang J, Hong Z, et al. Proportion of different subtypes of stroke in China. Stroke 2003;34:2091-6. 